\title{
Improving life expectancy in people with serious mental illness: should we place more emphasis on primary prevention?
}

Athif Ilyas, Edward Chesney and Rashmi Patel

\section{Summary}

People with serious mental illness have a reduced life expectancy that is partly attributable to increased cardiovascular disease. One approach to address this is regular physical health monitoring. However, physical health monitoring is poorly implemented in everyday clinical practice and there is little evidence to suggest that it improves physical health. We argue that greater emphasis should be placed on primary prevention strategies such as assertive smoking cessation, dietary and exercise interventions and more judicious psychotropic prescribing.

\section{Declaration of interest}

None.

\section{Copyright and usage}

(c) The Royal College of Psychiatrists 2017. This is an open access article distributed under the terms of the Creative commons Attribution (CC BY) licence.
People with serious mental illnesses such as schizophrenia or bipolar disorder have a substantially reduced life expectancy compared with the general population. ${ }^{1}$ Much of this reduction is attributable to a 2-3 times greater risk of cardiovascular morbidity and mortality, with the prevalence of cardiovascular disease up to 3.6 times greater in people with serious mental illness. ${ }^{2-4}$ Recent meta-analyses suggest around one in three people with serious mental illness has metabolic syndrome and one in ten has type 2 diabetes. ${ }^{5,6}$ Both meta-analyses demonstrated wide variation in prevalence depending on geographical distribution, diagnosis, treatment length and psychotropic prescribing. Baseline data from a large randomised controlled trial evaluating interventions to improve physical health outcomes has shown that cardiovascular risk factors are much more prevalent in people with serious mental illness compared with those without. ${ }^{7}$ The vast majority of participants in the trial were above the threshold for central obesity, and half the sample had a body mass index (BMI) $\geqslant 30 \mathrm{~kg} / \mathrm{m}^{2}$. Over half (57\%) were diagnosed with metabolic syndrome, and one in five met the criteria for type 2 diabetes. There is also evidence to suggest that second-generation antipsychotic treatment is associated with a higher risk of cardiovascular disease, due to increased weight gain, dyslipidaemia and impaired glucose regulation. ${ }^{8}$ Furthermore, people with serious mental illness have a much higher prevalence of smoking compared with the general population. ${ }^{9}$ Although smoking prevalence in the general population has reduced over the past few decades, smoking prevalence among people with serious mental illness has remained largely unchanged ${ }^{10}$ with over $60 \%$ of people with schizophrenia reporting current cigarette use. ${ }^{11}$

There has been a recent drive by the UK Department of Health and the National Institute for Health and Care Excellence (NICE) to implement regular physical health monitoring in people with serious mental illness in an attempt to improve their physical health. ${ }^{12}$ Within the published guidance, there has been a great deal of attention paid to monitoring of cardiovascular risk factors. We consider the evidence behind physical health monitoring, whether it is effective in reducing cardiovascular disease, and whether placing greater emphasis on strategies for primary prevention would be more effective in reducing premature mortality in people with serious mental illness.

\section{Clinical guidelines for physical health monitoring}

Since 2002, the Department of Health and NICE have provided an increasing amount of guidance on monitoring the physical health of people with serious mental illness (Appendix). Although guidelines were initially vague and called for annual or 'regular' monitoring, they have since become more explicit, with the most recent guidelines calling for much more frequent physical health monitoring: as often as weekly for weight monitoring during the first 6 weeks of starting an antipsychotic. In England, financial incentives are offered to mental healthcare providers who effectively deliver physical health monitoring as part of the commissioning for quality and innovation (CQUIN) scheme. ${ }^{13}$

Despite clear guidelines, the uptake of physical health monitoring in people with serious mental illness has been variable. A systematic review of studies investigating physical health monitoring for people prescribed antipsychotics found that the rates of screening varied from 25 to $70 \%$ but that rates improved after the implementation of guidelines for physical health monitoring. ${ }^{19}$ A study investigating rates of cardiovascular risk screening in UK general practices found that people with serious mental illness over the age of 60 were less likely to receive screening compared with people without serious mental illness. ${ }^{20}$

In 2014, NHS England, NHS Improving Quality, Public Health England and the National Audit of Schizophrenia Team coproduced the Lester UK Adaptation of the Positive Cardiometabolic Health Resource. ${ }^{21}$ The resource supports NICE guidelines on physical health monitoring in people with serious mental illness in an attempt to improve monitoring and also to encourage intervention in patients with abnormal physical health parameters. However, the degree to which detection of abnormal results leads to an intervention in those who undergo physical health monitoring remains uncertain.

\section{Evidence for physical health monitoring}

A greater understanding of the risk factors associated with cardiovascular disease has led to the development of clinical prediction rules such as the Framingham Score ${ }^{22}$ and QRISK ${ }^{23,24}$ to identify people at greater risk in the general population. More 
recently, a cardiovascular risk prediction tool for people with serious mental illness has been developed (PRIMROSE) ${ }^{25}$ and the QRISK tool has been updated to include severe mental illness and atypical antipsychotic medication as predictors of cardiovascular disease. ${ }^{26}$ Clinical prediction rules are used in physical health monitoring programmes to identify individuals at high risk who may benefit from interventions such as smoking cessation, antihypertensives and lipid-lowering therapies with the aim of reducing future cardiovascular morbidity and mortality. The National Health Service (NHS) health check programme is an example of a general population screening programme that offers physical health checks for adults aged between 40 and 74 in the UK at an annual cost of $£ 165$ million. ${ }^{27}$ A recent observational study evaluating the programme found that those who attended were more likely to be diagnosed with diabetes, hypertension and chronic kidney disease, and were more likely to be prescribed a statin than those who did not attend. ${ }^{28}$

However, several studies have indicated that physical health monitoring programmes have limited benefits in terms of reducing morbidity and mortality. ${ }^{29}$ A systematic review of 16 randomised trials investigating clinical outcomes of physical health monitoring found that although screening programmes resulted in an increase in the diagnosis of hypertension and hypercholesterolaemia, they had no significant impact on cardiovascular morbidity or mortality. ${ }^{30}$ Furthermore, a systematic review investigating the use of clinical prediction rules to screen for cardiovascular disease suggests that although cardiovascular disease risk assessment (and offering interventions to those considered to be at high risk) may result in reductions in blood pressure, cholesterol and smoking, there is no evidence that this strategy is associated with significant reductions in cardiovascular morbidity and mortality. ${ }^{31}$

Although the implementation of physical health screening programmes in the general population has been widely studied, a recent systematic review revealed there are no randomised clinical trials or economic evaluations investigating the effectiveness of physical health monitoring in people with serious mental illness. ${ }^{32}$ Therefore as of yet, there is no evidence to support the current NICE guidelines for physical health monitoring in people with serious mental illness.

\section{Improving physical health through intervention}

A number of strategies to improve physical health in people with serious mental illness have been investigated, including support for smoking cessation, dietary interventions, exercise interventions and avoiding prescription of antipsychotics associated with adverse metabolic outcomes. ${ }^{33}$ Such interventions are relevant to all patients with serious mental illness and not just those who are found to have abnormal results from physical health monitoring.

\section{Pharmacological support for smoking cessation}

Tobacco smoking rates in the UK general population have dropped considerably from $46 \%$ of adults in 1974 to $19 \%$ in $2016 .{ }^{34}$ However, around $60-70 \%$ of those with schizophrenia are smokers, making them more than three times as likely to smoke compared with the general population. ${ }^{11}$ A network meta-analysis has demonstrated that pharmacological therapies such as nicotine replacement therapy (NRT), bupropion and varenicline are effective in supporting smoking cessation in the general population. ${ }^{35}$ Bupropion and varenicline have also been found to significantly increase the chances of smoking cessation in people with schizophrenia. ${ }^{36}$ NRT and e-cigarettes could also help to support smoking cessation in people with mental disorders. ${ }^{37}$ However, prescribing data from UK general practices suggests that despite providing financial incentives to healthcare providers, there has been little change in the rates of prescribing pharmacological interventions to reduce smoking and prescription rates are likely to be lower in those with serious mental illness. ${ }^{38} \mathrm{~A}$ much more assertive strategy to promote smoking cessation using pharmacological interventions could lead to an enormous improvement in the physical health of people with serious mental illness. ${ }^{39}$

\section{Dietary and exercise interventions}

People with serious mental illness have a poorer diet than the general population. This may contribute towards obesity, dyslipidaemia and impaired glucose regulation, which can increase the risk of cardiovascular disease. ${ }^{40} \mathrm{~A}$ meta-analysis of randomised trials investigating dietary interventions in people with serious mental illness showed that dietary interventions result in a significant reduction in weight $(-2.7 \mathrm{~kg})$, BMI $\left(-0.87 \mathrm{~kg} / \mathrm{m}^{2}\right)$, waist circumference $(-2.3 \mathrm{~cm})$ and blood glucose levels $(-0.47 \mathrm{mmol} / \mathrm{L})$, particularly if interventions are led by dieticians. ${ }^{41}$

A review of randomised trials investigating exercise interventions in people with schizophrenia found no significant change in BMI but that exercise interventions may improve physical fitness and are associated with a reduction in psychiatric symptoms. ${ }^{42}$ However, reduced motivation can make it difficult to sustain adequate participation in exercise interventions. ${ }^{43}$ Exercise interventions that incorporate education and coaching sessions may help to improve uptake in people with serious mental illness who may otherwise have low levels of physical activity. ${ }^{44}$ In contrast, a systematic review investigating the effect of general physical health advice in people with serious mental illness found limited evidence for an improvement in outcomes. ${ }^{45}$ This suggests that improving diet and exercise in people with serious mental illness requires a more assertive approach than simply providing general health advice. However, there are relatively few studies investigating the cost-effectiveness of dietary and exercise interventions in people with serious mental illness and further evaluation is required to determine which interventions could be feasibly implemented in clinical practice. ${ }^{46}$

\section{Choice and duration of antipsychotic prescribing}

Some antipsychotics (particularly clozapine, olanzapine and risperidone) may contribute towards increased cardiovascular risk in people with serious mental illness because of increased weight gain, dyslipidaemia and impaired glucose regulation. ${ }^{8}$ There is growing debate about whether long-term treatment with antipsychotics is beneficial for all patients with schizophrenia, not only because of their adverse metabolic effects but also their long-term effects on brain structure and dopamine receptor function. ${ }^{47}$ This raises the question of whether psychiatrists should be more cautious about avoiding long-term prescription of antipsychotics associated with adverse metabolic effects in people with serious mental illness and to consider reducing or stopping these in patients at greater risk of cardiovascular disease. $^{48}$

\section{Conclusions}

People with serious mental illness die up to 20 years younger because of preventable physical disorders. ${ }^{1}$ In England, the NHS 


\section{Appendix}

\section{National Institute for Health and Care Excellence (NICE)/Department of Health guidelines on physical health monitoring in people with serious mental illness}

\begin{tabular}{|c|c|}
\hline Year & Description of guidelines \\
\hline 2002 & $\begin{array}{l}\text { NICE guidelines on schizophrenia are released (CG1) that state that clinicians should 'regularly monitor the physical health' of patients, } \\
\text { stating that 'particular attention should be paid to the risk of metabolic and cardiovascular disease'. }{ }^{14}\end{array}$ \\
\hline 2006 & $\begin{array}{l}\text { The Department of Health release best practice guidance for supporting the physical health needs of people with severe mental illness. }{ }^{15} \\
\text { The guidance states that patients should receive annual physical health check reviews, including blood tests and urinalysis, basic health } \\
\text { checks (including blood pressure, pulse and body mass index), and lifestyle review (including diet, physical activity and smoking). }\end{array}$ \\
\hline 2009 & $\begin{array}{l}\text { NICE guidelines on schizophrenia are updated (CG82) to recommend that patients should receive annual physical health check reviews, } \\
\text { with a 'focus on cardiovascular disease risk assessment'. }{ }^{16}\end{array}$ \\
\hline 2014 & $\begin{array}{l}\text { Current NICE guidelines on psychosis and schizophrenia in adults (CG178) recommend more frequent regular physical health monitoring } \\
\text { for patients receiving antipsychotic medication. The guidelines state the following physical health markers should be measured: }{ }^{12} \\
\text { (a) weight: baseline, then weekly for the first } 6 \text { weeks, at } 12 \text { weeks, at } 1 \text { year and then annually; } \\
\text { (b) waist circumference: baseline, and then annually; } \\
\text { (c) pulse and blood pressure: baseline, then at } 12 \text { weeks, at } 1 \text { year and then annually; } \\
\text { (d) fasting blood glucose, HbA1c and blood lipid levels: baseline, then at } 12 \text { weeks, at } 1 \text { year and then annually; } \\
\text { (e) overall physical health (nutritional status/diet/physical activity): baseline and at regular intervals. } \\
\text { There are similar NICE guidelines that recommend regular physical health monitoring for young people which psychosis and schizophrenia } \\
\text { (CG155), }{ }^{17} \text { and for patients with bipolar disorder (CG185). }{ }^{18}\end{array}$ \\
\hline
\end{tabular}

has attempted to address this issue by incentivising physical health monitoring programmes to reduce risk factors in those who are deemed to be at high risk of future cardiovascular events. ${ }^{13}$ However, there is no evidence that physical health monitoring in itself is effective in reducing cardiovascular risk in people with serious mental illness.

Healthcare services should consider a shift away from physical health monitoring strategies and instead focus their resources on primary prevention strategies that are provided to all people with serious mental illness from the moment they first present to mental healthcare services. These include assertive smoking cessation (with pharmacological support), diet and exercise interventions and where possible, to avoid long-term prescription of antipsychotics associated with adverse metabolic outcomes. This approach could help to substantially improve the long-term health and life expectancy of people with serious mental illness.

Athif Ilyas, Department of Psychology, Institute of Psychiatry, Psychology \& Neuroscience, King's College London, London, UK; Edward Chesney, BM, BCh, Rashmi Patel, BM, BCh, PhD, Department of Psychosis Studies, Institute of Psychiatry, Psychology \& Neuroscience, King's College London, London, UK

Correspondence: Rashmi Patel, Institute of Psychiatry, King's College London, Box PO 63, De Crespigny Park, Denmark Hill, London SE5 8AF, UK. Email: rcpsych@rpatel.co.uk

First received 13 Feb 2017, final revision 23 Apr 2017, accepted 26 May 2017

\section{Funding}

R.P. has received support from a UK Medical Research Council (MRC) Clinical Research Training Fellowship (MR/KO02813/1) and a Starter Grant for Clinical Lecturers (SGL015/ 1020) supported by the Academy of Medical Sciences, The Wellcome Trust, MRC, British 1020) supported by the Academy of Medical Sciences, The Wellcome Trust, MRC, British
Heart Foundation, Arthritis Research UK, the Royal College of Physicians and Diabetes UK.

\section{References}

1 Chesney E, Goodwin GM, Fazel S. Risks of all-cause and suicide mortality in mental disorders: a meta-review. World Psychiatry 2014; 13: 153-60.

2 Brown S, Kim M, Mitchell C, Inskip H. Twenty-five year mortality of a community cohort with schizophrenia. Br J Psychiatry 2010; 196: 116-21.

3 Osborn DP, Levy G, Nazareth I, Petersen I, Islam A, King MB. Relative risk of cardiovascular and cancer mortality in people with severe mental illness from the United Kingdom's General Practice Rsearch Database. Arch Gen Psychiatry 2007; 64: 242-9.

4 Crump C, Winkleby MA, Sundquist K, Sundquist J. Comorbidities and mortality in persons with schizophrenia: a Swedish national cohort study. Am J Psychiatry 2013; 170: 324-33.

5 Vancampfort D, Stubbs B, Mitchell AJ, De Hert M, Wampers M, Ward PB, et al. Risk of metabolic syndrome and its components in people with schizophrenia and related psychotic disorders, bipolar disorder and major depressive disorder: a systematic review and meta-analysis. World Psychiatry 2015; 14 339-47.

6 Vancampfort D, Correll CU, Galling B, Probst M, De Hert M, Ward PB, et al. Diabetes mellitus in people with schizophrenia, bipolar disorder and major depressive disorder: a systematic review and large scale meta-analysis. World Psychiatry 2016; 15: 166-74

7 Gardner-Sood P, Lally J, Smith S, Atakan Z, Ismail K, Greenwood KE, et al. Cardiovascular risk factors and metabolic syndrome in people with established psychotic illnesses: baseline data from the IMPaCT randomized controlled trial. Psychol Med 2015; 45: 2619-29.

8 Mitchell AJ, Vancampfort D, Sweers K, van Winkel R, Yu W, De Hert M Prevalence of metabolic syndrome and metabolic abnormalities in schizophrenia and related disorders-a systematic review and meta-analysis. Schizophr Bull 2013; 39: 306-18.

9 Cook B, Wayne G, Kafali E, Liu Z, Shu C, Flores M. Trends in smoking among adults with mental illness and association between mental health treatment and smoking cessation. JAMA 2014; 311: 172-82.

10 Szatkowski L, McNeill A. Diverging trends in smoking behaviors according to mental health status. Nicotine Tob Res 2015; 17: 356-60.

11 Dickerson $F$, Stallings $C R$, Origoni $A E$, Vaughan $C$, Khushalani S, Schroeder J, et al. Cigarette smoking among persons with schizophrenia or bipolar disorder in routine clinical settings, 1999-2011. Psychiatr Serv 2013; 64 $44-50$.

12 National Institute for Health and Care Excellence. Psychosis and Schizophrenia in Adults: Prevention and Management. NICE Clinical Guideline 178. NICE, 2014

13 NHS England. Commissioning for Quality and Innovation (CQUIN). NHS England, 2016 (https://www.england.nhs.uk/wp-content/uploads/2016/03/ cquin-guidance-16-17-v3.pdf)

14 National Institute for Health and Care Excellence. Schizophrenia. NICE Clinical Guideline 1. NICE, 2002

15 Department of Health. Choosing Health: Supporting the Physical Needs of People with Severe Mental Illness. Department of Health, 2006.

16 National Institute for Health and Care Excellence. Psychosis and Schizophrenia: Management. NICE Clinical Guideline 82. NICE, 2009.

17 National Institute for Health and Care Excellence. Psychosis and Schizophrenia in Children and Young People: Recognition and Management. NICE Clinical Guideline 155. NICE, 2013

18 National Institute for Health and Care Excellence. Bipolar Disorder: Assessment and Management. NICE Clinical Guideline 185. NICE, 2014 
19 Mitchell AJ, Delaffon V, Vancampfort D, Correll CU, De Hert M. Guideline concordant monitoring of metabolic risk in people treated with antipsychotic medication: systematic review and meta-analysis of screening practices. Psychol Med 2012; 42: 125-47.

20 Osborn DPJ, Baio G, Walters K, Petersen I, Limburg H, Raine R, et al. Inequalities in the provision of cardiovascular screening to people with severe mental illnesses in primary care. Cohort study in the United Kingdom THIN Primary Care Database 2000-2007. Schizophr Res 2011; 129: 104-10.

21 Shiers DE, Rafi I, Cooper SJ, Holt RIG. 2014 update (with acknowledgement to the late Helen Lester for her contribution to the original 2012 version). Positive Cardiometabolic Health Resource: an intervention framework for patients with psychosis and schizophrenia. Royal College of Psychiatrists, 2014 (https://www.rcpsych.ac.uk/pdf/Lester\%20update\%20June\%202014 \%2OFINAL.pdf)

22 D'Agostino RB, Vasan RS, Pencina MJ, Wolf PA, Cobain M, Massaro JM, et al. General cardiovascular risk profile for use in primary care. Circulation 2008 ; 117: 743-53.

23 Hippisley-Cox J, Coupland C, Vinogradova Y, Robson J, May M, Brindle P. Derivation and validation of QRISK, a new cardiovascular disease risk score for the United Kingdom: prospective open cohort study. BMJ 2007; 335: 136

24 Hippisley-Cox J, Coupland C, Vinogradova Y, Robson J, Minhas R, Sheikh A, et al. Predicting cardiovascular risk in England and Wales: prospective derivation and validation of QRISK2. BMJ 2008; 336: 1475-82.

25 Osborn DPJ, Hardoon S, Omar RZ, Holt RIG, King M, Larsen J, et al. Cardiovascular risk prediction models for people with severe mental illness: results from the prediction and management of cardiovascular risk in people with severe mental illnesses (PRIMROSE) research program. JAMA Psychiatry 2015; 72: 143-51.

26 Hippisley-Cox J, Coupland C, Brindle P. Development and validation of QRISK3 risk prediction algorithms to estimate future risk of cardiovascular disease: prospective cohort study. BMJ 2017; 357: 2099.

27 Robson J, Dostal I, Sheikh A, Eldridge S, Madurasinghe V, Griffiths C, et al. The NHS Health Check in England: an evaluation of the first 4 years. BMJ Open 2016; 6: e008840.

28 Robson J, Dostal I, Madurasinghe V, Sheikh A, Hull S, Boomla K, et al. NHS Health Check comorbidity and management: an observational matched study in primary care. $\mathrm{Br} J$ Gen $\operatorname{Pr} 2017$; 67: e86-93.

29 Gøtzsche PC, Jørgensen KJ, Krogsbøll LT. General health checks don't work. BMJ 2014; 348: g3680.

30 Krogsbøll LT, Jørgensen KJ, Larsen CG, Gøtzsche PC. General health checks in adults for reducing morbidity and mortality from disease: Cochrane systematic review and meta-analysis. BMJ 2012; 345: e7191.

31 Collins DRJ, Tompson AC, Onakpoya IJ, Roberts N, Ward AM, Heneghan CJ. Global cardiovascular risk assessment in the primary prevention of cardiovascular disease in adults: systematic review of systematic reviews. BMJ Open 2017; 7: e013650.

32 Tosh G, Clifton AV, Xia J, White MM. Physical health care monitoring for people with serious mental illness. Cochrane Database Syst Rev 2014; 1 CD008298.
33 Baxter AJ, Harris MG, Khatib Y, Brugha TS, Bien H, Bhui K. Reducing excess mortality due to chronic disease in people with severe mental illness: meta-review of health interventions. Br J Psychiatry 2016; 208: 322-9.

34 Health and Social Care Information Centre. Statistics on Smoking. HSCIC, 2016 (http://content.digital.nhs.uk/catalogue/PUB20781/stat-smok-eng-2016rep.pdf).

35 Cahill K, Stevens S, Perera R, Lancaster T. Pharmacological interventions for smoking cessation: an overview and network meta-analysis. Cochrane Database Syst Rev 2013; 5: CD009329.

36 Tsoi DT, Porwal M, Webster AC. Interventions for smoking cessation and reduction in individuals with schizophrenia. Cochrane Database Syst Rev 2013; 2: CD007253.

37 O'Brien B, Knight-West O, Walker N, Parag V, Bullen C. E-cigarettes versus NRT for smoking reduction or cessation in people with mental illness: secondary analysis of data from the ASCEND trial. Tob Induc Dis 2015; 13: 5 .

38 Szatkowski L, Aveyard P. Provision of smoking cessation support in UK primary care: impact of the 2012 QOF revision. Br J Gen Pract 2015; 66: e10-15

39 Gaballa D, Drowos J, Hennekens $\mathrm{CH}$. Smoking cessation: the urgent need for increased utilization of varenicline. Am J Med 2017; 130: 389-91.

40 Dipasquale S, Pariante CM, Dazzan P, Aguglia E, McGuire P, Mondelli V. The dietary pattern of patients with schizophrenia: a systematic review. J Psychiatr Res 2013; 47: 197-207.

41 Teasdale SB, Ward PB, Rosenbaum S, Samaras K, Stubbs B. Solving a weighty problem: systematic review and meta-analysis of nutrition interventions in severe mental illness. Br J Psychiatry 2017; 210: 110-8.

42 Firth J, Cotter J, Elliott R, French $P$, Yung AR. A systematic review and meta-analysis of exercise interventions in schizophrenia patients. Psychol Med 2015; 45: 1343-61.

43 Buhagiar K, Parsonage L, Osborn DP. Physical health behaviours and health locus of control in people with schizophrenia-spectrum disorder and bipolar disorder: a cross-sectional comparative study with people with nonpsychotic mental illness. BMC Psychiatry 2011; 11: 104.

44 Williams J, Stubbs B, Gaughran F, Craig T. 'Walk This Way' - a pilot of a health coaching intervention to reduce sedentary behaviour and increase low intensity exercise in people with serious mental illness: study protocol for a randomised controlled trial. Trials 2016; 17: 594.

45 Tosh G, Clifton AV, Xia J, White MM. General physical health advice for people with serious mental illness. Cochrane Database Syst Rev 2014; 3 : CD008567.

46 Park A-L, McDaid D, Weiser P, Von Gottberg C, Becker T, Kilian R. Examining the cost effectiveness of interventions to promote the physical health of people with mental health problems: a systematic review. BMC Public Health 2013; 13: 787.

47 Moncrieff J. Antipsychotic maintenance treatment: time to rethink? PLOS Med 2015; 12: e1001861.

48 Murray RM, Quattrone D, Natesan S, van Os J, Nordentoft M, Howes O, et al. Should psychiatrists be more cautious about the long-term prophylactic use of antipsychotics? Br J Psychiatry 2016; 209: 361-5. 